\title{
Urinary cell-free mitochondrial and nuclear deoxyribonucleic acid correlates with the prognosis of chronic kidney diseases
}

\author{
Chia-Chu Chang ${ }^{1,2,3}$, Ping-Fang Chiu ${ }^{3,4,5,6}$, Chia-Lin $\mathrm{Wu}^{4,7}$, Cheng-Ling Kuo ${ }^{5}$, Ching-Shan Huang ${ }^{5}$, \\ Chin-San Liu ${ }^{5,8+}$ and Ching-Hui Huang ${ }^{5,9,10,11,12^{*}+}$
}

\begin{abstract}
Introduction: Cell-free deoxyribonucleic acid DNA (cf-DNA) in urine is promising due to the advantage of urine as an easily obtained and non-invasive sample source over tissue and blood. In clinical practice, it is important to identify non-invasive biomarkers of chronic kidney disease (CKD) in monitoring and surveillance of disease progression. Information is limited, however, regarding the relationship between urine and plasma cf-DNA and the renal outcome in CKD patients.

Methods: One hundred and thirty-one CKD patients were enrolled between January 2016 and September 2018. Baseline urine and plasma cell-free mitochondrial DNA (cf-mtDNA) and cell-free nuclear DNA (cf-nDNA) were isolated using quantitative real-time PCR. Estimated glomerular filtration rate (eGFR) measurement was performed at baseline and 6-month follow-up. Favorable renal outcome was defined as eGFR at 6 months minus baseline eGFR $>=0$. Receiver operator characteristics (ROC) curve analysis was performed to assess different samples of cfDNA to predict favorable renal outcomes at 6 months. A multivariate linear regression model was used to evaluate independent associations between possible predictors and different samples of cf-DNA.

Results: Patients with an advanced stage of CKD has significantly low plasma cf-nDNA and high plasma neutrophil gelatinase-associated lipocalin (NGAL) levels. Low urine cf-mtDNA, cf-nDNA levels and low plasma NGAL were significantly correlated with favorable renal outcomes at 6 months. The urine albumin-creatinine ratio (ACR) or urine protein-creatinine ratio (PCR) level is a robust predictor of $\mathrm{cf}-\mathrm{mtDNA}$ and $\mathrm{cf-nDNA}$ in CKD patients. Baseline urine levels of $\mathrm{cf}-\mathrm{mtDNA}$ and $\mathrm{cf}$ nDNA could predict renal outcomes at 6 months.
\end{abstract}

Conclusions: Urinary cf-mtDNA and cf-nDNA may provide novel prognostic biomarkers for renal outcome in CKD patients. The levels of plasma of-nDNA and plasma NGAL are significantly correlated with the severity of CKD.

Keywords: Cell-free mitochondrial deoxyribonucleic acid, Cf-mtDNA, Cell-free nuclear deoxyribonucleic acid, Cf-nDNA, Neutrophil gelatinase-associated lipocalin, NGAL, Chronic kidney disease

\section{Background}

Chronic kidney disease (CKD) is a global public health problem affecting up to $10 \%$ of the population worldwide [1], although guidelines for the clinical staging of CKD have been established [2]. The natural history of the earlier phases of CKD are highly unpredictable and the early identification of

\footnotetext{
* Correspondence: 28071@cch.org.tw

${ }^{+}$Chin-San Liu and Ching-Hui Huang contributed equally to this work.

${ }^{5}$ Vascular \& Genomic Research Center, Changhua Christian Hospital, Changhua, Taiwan

${ }^{9}$ Department of Cardiology, Changhua Christian Hospital, Changhua, Taiwan Full list of author information is available at the end of the article
}

CKD and timely detection of progression are truly global challenges [3, 4]. It is important to recognize the risk factors of CKD, and better approaches for the prevention, early detection, and treatment of CKD [5].

The kidney is a highly energetic organ and rich in mitochondria and numerous studies have shown that mitochondrial dysfunction contributes to different types of kidney diseases, including diabetic and nondiabetic nephropathy [6]. Proteinuria, caused by a primary insult to the kidney, induces oxidative stress in renal tubular cells and causes mitochondrial dysfunction $[7,8]$, which leads to cellular damage by

(c) The Author(s). 2019 Open Access This article is distributed under the terms of the Creative Commons Attribution 4.0 International License (http://creativecommons.org/licenses/by/4.0/), which permits unrestricted use, distribution, and 
reactive oxygen species generation as well as epithelial-mesenchymal transition (EMT) $[9,10]$. To date, CKD is characterized by mitochondrial dysfunction, oxidative stress, and aberrant autophagy $[11,12]$ in addition to significant changes in the activation of transforming growth factor- $\beta$, p53, hypoxia-inducible factor, chronic inflammation, and traditional vascular dysfunction [11]. By the experimental models of $\mathrm{CKD}$, preventing mitochondrial dysfunction inhibits renal tubular cell EMT and renal fibrosis [13]. However, only a relatively small number of translational studies have shown the clinical relevance of these mechanisms between renal diseases and mitochondrial dysfunction in humans $[6,14,15]$.

Free circulating nucleic acids, cell-free deoxyribonucleic acid (cf-DNA), were discovered in human plasma in 1948 by Mandel and Metais [16]. Some studies showed the damaged mitochondria release their DNA content into the systemic circulation $[17,18]$. Thus, cell-free mitochondrial deoxyribonucleic acid (cf-mtDNA) is easily detected in plasma, and has been explored as a biomarker of various diseases [19-21]. Recently, increased plasma levels of cf-mtDNA have been reported to correlate with the severity of injury in patients sustaining polytrauma [22] and the severity of stroke [23], be a prognostic marker of acute myocardial infarction [24] and intensive care unit patients $[25,26]$. Alterations of cf-mtDNA in the blood also might be associated with several systemic diseases, including primary mitochondrial disorders, carcinogenesis, and hematologic diseases $[27,28]$. In a community-based population cohort, higher plasma cf-mtDNA was associated with a lower incidence of CKD independent of traditional risk factors [20] and was associated with a lower prevalence of microalbuminuria [29]. Apart from blood, cf-DNA could also be detected in urine. Urine cf-DNA originates either from cells shedding into urine from genitourinary tract, or from cell free DNA in circulation passing through glomerular filtration [30]. The presence of genetic information in urine has been observed in some clinical studies. For examples, the urinary cf-mtDNA level had statistically significant correlations with the peak serum creatinine level and the duration of hospitalization in a study of acute kidney injury (AKI) [30]. Patients who required temporary dialysis also tended to have higher urinary cf-mtDNA levels than those without dialysis [31], but no relationship between the urinary cf-mtDNA level and renal outcomes has been reported. A recent study showed that urinary cf-mtDNA level was increased in mice after 10-15 min of ischemia, and that the level correlated with the duration of ischemia [32]. Otherwise, platelet and leukocyte counts in samples are important sources of variation when cf-DNA is measured in DNA extracted from whole blood [27, 28]. Emerging data showed that measuring cf-DNA extracted from whole blood (nuclear deoxyribonucleic acid, cf-nDNA) could yield different results from peripheral blood mononuclear cells or buffy coat (cf-mtDNA), because of the presence of mitochondrial DNA in platelets $[27,28]$.
Since the majority of urine cf-DNA originates from apoptosis or necrosis of cells exfoliated from urogenital system [30]. And the minority are originating from blood circulation, which contains important genomic information from various positions all over the body [33,34]. We postulate that urine cf-DNA might be regarded as a marker which combined genetic information from urogenital system and systemic. We hypothesis that urinary cf-DNA might be a better novel biomarker than circulating cf-DNA in predicting renal outcome in CKD patients. To clarify the clinical application of cf-mtDNA and cf-nDNA in CKD, we studied the correlation between cf-mtDNA and cf-nDNA, both urine and plasma, and the stage of CKD or prognosis of renal outcomes.

\section{Methods}

The Institutional Review Board of Changhua Christian Hospital approved the experimental protocols (approval number 140306) and all the participants provided written informed consent to participate the study. All patients of the study joined our nationwide preventive multidisciplinary program, also regulated by the Clinical Care Program Certification and Joint Commission International, for early CKD or pre-ESRD (end stage renal disease). We investigated patients who were enrolled in our CKD care program between January 2016 and September 2018.The goals for patients' blood pressure, glucose and lipid control were based on the KDOGI guidelines.

Overall, of 131 patients with CKD, 7 patients dropped-out for the duration of follow-up less than 6 months, and 52 volunteers were recruited from the Nephrology Clinic at Changhua Christian Hospital, a tertiary referral hospital in Taiwan. The duration of follow-up for CKD was more than 6 months in all patients. The patients with following criteria were excluded: infection, acute fever, hepatic or cardiac disease, endocrinopathy, glomerulonephritis proved by biopsy or treatment with steroids or immunosuppressants, surgery, trauma, missing data at baseline, prior kidney transplant, acute kidney injury and a history of RRT or hospitalization for any cause in the past 3 months. The amount of proteinuria was calculated by urinary protein-creatinine ratio $(\mathrm{PCR}, \mathrm{mg} / \mathrm{g}$ ) or albumincreatinine ratio (ACR, mg/g). Microalbuminuria was established when two out of three ACR determinations were found to be within the range of $30-300 \mathrm{mg} / \mathrm{g}$ in a 6-month period. We calculated the glomerular filtration rate (eGFR) of the patients according to the CKD Epidemiology Collaboration equation (eGFR CKD-EPI [35]. The stages of CKD were defined as follows: stage 1 , eGFR $>90 \mathrm{ml} / \mathrm{min} / 1.73 \mathrm{~m}^{2}$; stage 2 , eGFR $60-89 \mathrm{ml} / \mathrm{min} / 1.73 \mathrm{~m}^{2}$; stage $3 \mathrm{a}$, eGFR $45-59 \mathrm{ml} / \mathrm{min} / 1.73$ $\mathrm{m}^{2}$; stage $3 \mathrm{~b}$, eGFR $30-44 \mathrm{ml} / \mathrm{min} / 1.73 \mathrm{~m}^{2}$; stage 4 , eGFR $15-$ $29 \mathrm{ml} / \mathrm{min} / 1.73 \mathrm{~m}^{2}$ and stage 5 , eGFR $<15 \mathrm{ml} / \mathrm{min} / 1.73 \mathrm{~m}^{2}$ or maintenance on RRT. We divided the population to early CKD (stages 1-3a) and advanced CKD (stages $3 \mathrm{~b}-5$ ) in the study, based on our national CKD care program. 
Table 1 Demographic characteristics of varying stages of chronic kidney disease

\begin{tabular}{|c|c|c|c|c|c|c|}
\hline \multirow[t]{2}{*}{ Variables } & \multirow{2}{*}{$\begin{array}{l}\text { Stage } 1,2^{a} \\
n=23\end{array}$} & \multirow{2}{*}{$\begin{array}{l}\text { Stage } 3 A^{b} \\
n=28\end{array}$} & \multirow{2}{*}{$\begin{array}{l}\text { Stage } 3 B^{c} \\
n=31\end{array}$} & \multirow{2}{*}{$\begin{array}{l}\text { Stage } 4,5^{d} \\
n=42\end{array}$} & \multirow[t]{2}{*}{$p$ value } & \multirow[t]{2}{*}{ Post hoc } \\
\hline & & & & & & \\
\hline Age (year) & $47.1 \pm 12.7$ & $53.6 \pm 9.4$ & $54.9 \pm 10.5$ & $58.7 \pm 6.1$ & $0.002^{*}$ & $a<c, d$ \\
\hline Gender (M/F) & $3 / 20$ & $8 / 20$ & $22 / 9$ & 29/13 & 0.212 & \\
\hline Hypertension (\%) & $42 \%$ & $37 \%$ & $59 \%$ & $54 \%$ & 0.191 & \\
\hline Diabetes mellitus (\%) & $12 \%$ & $11 \%$ & $23 \%$ & $54 \%$ & 0.160 & \\
\hline Systolic blood pressure $(\mathrm{mm} \mathrm{Hg})$ & $138 \pm 18$ & $144 \pm 28$ & $138 \pm 24$ & $142 \pm 15$ & 0.943 & \\
\hline Diastolic blood pressure (mm Hg) & $90 \pm 15$ & $91 \pm 4$ & $84 \pm 18$ & $84 \pm 12$ & 0.784 & \\
\hline $\mathrm{BMI}\left(\mathrm{kg} / \mathrm{m}^{2}\right)$ & $27.8 \pm 5.4$ & $28.2 \pm 6.1$ & $26.2 \pm 6.1$ & $24.8 \pm 4.3$ & 0.172 & \\
\hline BUN (mg/dL) & $14.3 \pm 4.4$ & $17.7 \pm 3.8$ & $31.4 \pm 13.0$ & $64.5 \pm 27.1$ & $<0.001^{* *}$ & $a, b<c<d$ \\
\hline eGFR (ml/min/1.73 m^2) & $84.4 \pm 20.2$ & $52.1 \pm 4.4$ & $31 \pm 9.6$ & $11.5 \pm 7.3$ & $<0.001^{* *}$ & $a>b>c>d$ \\
\hline Phosphate (mg/dL) & $3.5 \pm 0.4$ & $3.5 \pm 0.6$ & $4.0 \pm 0.7$ & $5.0 \pm 1.1$ & $<0.001^{* *}$ & $a, b, c<d$ \\
\hline Cholesterol (mg/dL) & $198.3 \pm 50.4$ & $171.5 \pm 31.8$ & $196.6 \pm 47.3$ & $153.3 \pm 44.5$ & $0.001^{* *}$ & $a, c>d$ \\
\hline $\mathrm{HDL}-\mathrm{C}(\mathrm{mg} / \mathrm{dL})$ & $47.8 \pm 14.3$ & $43.3 \pm 9.8$ & $46.1 \pm 12.6$ & $46.7 \pm 21.2$ & 0.677 & \\
\hline LDL-C (mg/dL) & $118.2 \pm 45.3$ & $104.6 \pm 31.4$ & $114.9 \pm 41.3$ & $80.8 \pm 26.7$ & $0.040^{*}$ & $c>d$ \\
\hline Fasting Glucose (mg/dL) & $118.3 \pm 46.1$ & $106 \pm 21.8$ & $112.6 \pm 43.5$ & $94.9 \pm 24.6$ & 0.263 & \\
\hline $\mathrm{HbA1C}(\%)$ & $6.3 \pm 1.4$ & $6.0 \pm 0.6$ & $6.2 \pm 1.1$ & $6.1 \pm 0.9$ & 0.778 & \\
\hline Urine $A / C$ ratio (mg/g) & $438.0 \pm 826.4$ & $535.7 \pm 1018.4$ & $2121.3 \pm 2540.7$ & $1548.0 \pm 2377.2$ & 0.058 & \\
\hline $\mathrm{WBC}\left(\times 10^{3} / \mu \mathrm{L}\right)$ & $7.1 \pm 2.4$ & $6.2 \pm 1.9$ & $6.4 \pm 2.1$ & $6.8 \pm 2.0$ & 0.323 & \\
\hline Uric Acid (mg/dL) & $7.1 \pm 1.2$ & $7.0 \pm 1.4$ & $7.5 \pm 2.6$ & $7.0 \pm 1.2$ & 0.629 & \\
\hline Platelet $\left(\times 10^{3} / \mu \mathrm{L}\right)$ & $230.2 \pm 72.6$ & $209.2 \pm 59.5$ & $201.9 \pm 51.1$ & $195.1 \pm 58.2$ & 0.159 & \\
\hline
\end{tabular}

$P$-value by One-Way ANOVA follow with Bonferroni multiple comparisons at type I error of 0.05 level

${ }^{*} P<0.05$, ${ }^{* *} P<0.01$. Gender (M/F), female/male; BMI, body mass index; BUN, blood urea nitrogen; HDL, high-density lipoprotein; LDL, low-density lipoprotein; $\mathrm{HbA} 1 \mathrm{C}$, glycated hemoglobin; WBC, white blood count; eGFR, estimated glomerular filtration rate; urine A/C ratio, urine albumin-creatinine ratio Post hoc: ${ }^{a}$ indicates group stage 1,$2 ;{ }^{b}$ indicates group stage $3 a$; ${ }^{c}$ indicates group stage $3 b$; ${ }^{d}$ indicates group stage 4,5

Studies in CKD always address primary outcomes of death, ESRD, or doubling of baseline serum creatinine. Coresh et al. extended use of percentage reduction in eGFR as a surrogate for hard outcomes and they reported that longer-term follow-up, more than 1 year, was strongly predictive of ESRD and death [36]. We, therefore, examined the change of eGFR as a surrogate for hard outcomes within 6 months. For study simplicity, favorable renal outcome was defined as eGFR at
6 months minus baseline eGFR $>=0$; unfavorable renal outcome indicated eGFR at 6 months minus baseline eGFR $<0$.

\section{Blood, plasma and urine sampling}

Participants' venous blood samples, following 8-h overnight fasting, were obtained and first morning urine samples were collected. Aliquots of urine were immediately frozen at $-80^{\circ} \mathrm{C}$ until further analysis, but specimen reserved for

Table 2 The levels of different parameters in varying stages of CKD

\begin{tabular}{|c|c|c|c|c|c|c|}
\hline & Stage $1,2^{a}$ & Stage $3^{b}$ & Stage $3^{c}$ & Stage $4,5^{d}$ & $P$ value & Post hoc tests \\
\hline Plasma cf-mtDNA (GE/mL) & $523 \pm 710$ & $373 \pm 360$ & $420 \pm 664$ & $112 \pm 134$ & 0.209 & \\
\hline Plasma cf-nDNA (GE/mL) & $1269 \pm 1195$ & $698 \pm 527$ & $439 \pm 569$ & $104 \pm 70.01$ & $<0.001^{* *}$ & $a>b, c, d$ \\
\hline Urine cf-mtDNA (GE/mL) & $0.43 \pm 0.69$ & $0.98 \pm 3.10$ & $2.78 \pm 10.12$ & $6.49 \pm 17.85$ & 0.220 & \\
\hline Urine cf-nDNA (GE/mL) & $2.83 \pm 4.60$ & $4.49 \pm 12.09$ & $15.39 \pm 44.01$ & $8.01 \pm 12.08$ & 0.351 & \\
\hline Plasma NGAL (ng/mL) & $394 \pm 175$ & $489.6 \pm 174.9$ & $744.2 \pm 272.1$ & $1096 \pm 488.7$ & $<0.001^{* *}$ & $a, b,<c, d$ \\
\hline MCN (per cell) & $90.7 \pm 66.9$ & $94.9 \pm 77.01$ & $92.9 \pm 89.9$ & $110.5 \pm 112.7$ & 0.901 & \\
\hline Urine $8-\mathrm{OH} \mathrm{dG} / \mathrm{Cr}$ & $3.73 \pm 1.81$ & $3.78 \pm 2.93$ & $4.15 \pm 2.65$ & $2.99 \pm 1.53$ & 0.416 & \\
\hline
\end{tabular}

$P$-value by One-Way ANOVA follow with Bonferroni multiple comparisons at type I error of 0.05 level ${ }^{*} P<0.05, * * P<0.01$

Post hoc ${ }^{a}$ indicates group stage 1,$2 ;{ }^{b}$ indicates group stage $3 a ;{ }^{c}$ indicates group stage $3 b ;{ }^{d}$ indicates group stage 4,5

$M C N$ mitochondrial copy number, NGAL neutrophil gelatinase-associated lipocalin; 8-OH dG 8-hydroxy-2-deoxyguanosine, cf-mtDNA cell-free mitochondrial DNA, $c f-n D N A$ cell-free nuclear DNA, GE/mL genome equivalents $/ \mathrm{mL}$ 
Table 3 The difference of baseline parameters between favorable and unfavorable renal outcome at 6 months

\begin{tabular}{llll}
\hline & $\begin{array}{l}\text { Favorable renal outcome } \\
(n=53)\end{array}$ & $\begin{array}{l}\text { Unfavorable renal outcome } \\
(n=70)\end{array}$ & $P$ value \\
\hline Plasma cf-mtDNA (GE/mL) & $441.1 \pm 525.6$ & $370.6 \pm 641.9$ & 0.538 \\
Plasma cf-nDNA (GE/mL) & $760.9 \pm 732.9$ & $554.1 \pm 850.9$ & 0.184 \\
Urine cf-mtDNA (GE/mL) & $0.489 \pm 0.751$ & $3.745 \pm 12.197$ & $0.027^{*}$ \\
Urine cf-nDNA (GE/mL) & $1.764 \pm 2.388$ & $15.119 \pm 40.791$ & $0.009^{*}$ \\
MCN (per cell) & $87.21 \pm 69.40$ & $101.55 \pm 95.75$ & 0.356 \\
Urine 8-OH dG/Cr & $3.62 \pm 2.44$ & $4.03 \pm 2.44$ & 0.346 \\
NGAL (ng/mL) & $585.24 \pm 251.62$ & $780.85 \pm 391.39$ & $0.032^{*}$ \\
\hline
\end{tabular}

$* P<0.05$, Student's test

MCN, mitochondrial copy number; NGAL, neutrophil gelatinase-associated lipocalin; 8-OH dG, 8-hydroxy-2-deoxyguanosine; cf-mtDNA, cell-free mitochondrial DNA; cf-nDNA, cell-free nuclear DNA; GE/mL, genome equivalents $/ \mathrm{mL}$

Favorable renal outcome indicated eGFR at 6 months minus baseline eGFR $>=0$; unfavorable renal outcome indicated eGFR at 6 months minus baseline eGFR $<0$

no longer than 1 month. All assays were undertaken in duplicate with intra-assay variation coefficient less than $5 \%$. Urinary albumin concentration was measured by an immunoturbidimetric method (Roche Diagnostics GmbH, Mannheim, Germany).

\section{DNA isolation and qPCR}

The baseline data of urine and plasma cell-free mitochondrial DNA (cf-mtDNA) and cell-free nuclear DNA (cf-nDNA) were isolated from 131 patients with CKD in our study. Blood collection were drawn from each subject in the morning after overnight fasting $8 \mathrm{~h}$. For each subject, $5 \mathrm{ml}$ of whole blood was withdrawn from an antecubital vein and quickly delivered into an EDTA-K3-containing plastic tube. Plasma was collected by centrifugation of blood at $2500 \mathrm{rpm}$ for $10 \mathrm{~min}$, divided into several aliquots, and stored in $-80^{\circ} \mathrm{C}$ until analysis. Urine samples were placed on $4^{\circ} \mathrm{C}$, centrifuged at $12000 \mathrm{rpm}$ for $15 \mathrm{~min}$ within $8 \mathrm{~h}$ of collection, and the urine supernatants were separated and stored at $-80^{\circ} \mathrm{C}$ until extraction DNA. Plasma and Urine cfDNA was extracted urine the Viral DNA mini Kit (AccuBioMed, Co, Ltd., Taiwan), following the protocol of manufacturer.

Table 4 Univariate correlation between urinary cf-nDNA and variables

\begin{tabular}{lll}
\hline Variable & Rho correlation coefficient & $P$ value \\
\hline Urine A/C ratio $(\mathrm{mg} / \mathrm{g})$ & 0.408 & $0.005^{*}$ \\
Urine $\mathrm{P} / \mathrm{C}$ ratio $(\mathrm{mg} / \mathrm{g})$ & 0.314 & $0.007^{*}$ \\
Urine $\mathrm{ff}-\mathrm{mtDNA}(\mathrm{GE} / \mathrm{mL})$ & 0.448 & $<0.001^{* *}$ \\
Urine protein $(\mathrm{mg} / \mathrm{dL})$ & 0.246 & $0.029^{*}$ \\
NGAL $(\mathrm{ng} / \mathrm{mL})$ & 0.322 & $0.001^{* *}$ \\
\hline
\end{tabular}

${ }^{*} P<0.05,{ }^{* *} P<0.01$; Spearman's rho correlation $\mathrm{NGAL}$, neutrophil gelatinase-associated lipocalin $(\mathrm{ng} / \mathrm{mL})$; cf-mtDNA, cell-free mitochondrial DNA $(\mathrm{GE} / \mathrm{mL}) ; \mathrm{GE} / \mathrm{mL}$, genome equivalents $/ \mathrm{mL}$; urine $\mathrm{A} / \mathrm{C}$ ratio, urine albumin-creatinine ratio $(\mathrm{mg} / \mathrm{g})$; urine $\mathrm{P} / \mathrm{C}$ ratio, urine protein-creatinine ratio $(\mathrm{mg} / \mathrm{g})$

\section{Leukocyte mitochondrial DNA copy number}

We used a LightCycler 480 Instrument (Roche, Mannheim, Germany) to measure mitochondrial copy number (MCN) in leukocytes. Briefly, we extracted total DNA using the Gentra Puregene DNA kit (Qiagen, Hilden, Germany). Realtime polymerase chain reaction (PCR) was used to amplify the ND1 gene of mtDNA and $\beta$-globin of nuclear DNA, respectively. The relative $\mathrm{MCN}$ of mtDNA was normalized to the $\beta$-globin gene.

\section{Quantification of urine and plasma cell-free DNA by real- time PCR}

Baseline urine and plasma cf-mtDNA and cf-nDNA were quantified by real-time PCR using the LightCycler ${ }^{\circ} 480 \mathrm{In}$ strument (Roche, Mannheim, Germany) using specific primers to amplify the $\beta$-globin (forward: $5^{\prime}$-GTG CAC CTG ACT CCT GAG GAG A-3', reverse: $5^{\prime}$-CCT TGA TAC CAA CCT GCC CAG-3') and MT-ND1 (forward: AACATACCCATGGCCAACCT, reverse: AGCGAA GGGTTGTAGTAGCCC) genes from urine and plasma DNA, and standard regression analyses were used to derive the amount of urine and plasma nuclear DNA and

Table 5 Univariate correlation between urinary cf-mtDNA and variables

\begin{tabular}{lll}
\hline Variable & Rho correlation coefficient & $P$ value \\
\hline Urine A/C ratio $(\mathrm{mg} / \mathrm{g})$ & 0.375 & $0.008^{*}$ \\
Urine P/C ratio $(\mathrm{mg} / \mathrm{g})$ & 0.349 & $0.002^{* *}$ \\
Urine $\mathrm{ff}-\mathrm{nDNA}(\mathrm{GE} / \mathrm{mL})$ & 0.448 & $<0.001^{* *}$ \\
Urine protein $(\mathrm{mg} / \mathrm{dL})$ & 0.167 & 0.125 \\
$\mathrm{NGAL}(\mathrm{ng} / \mathrm{mL})$ & 0.168 & 0.066 \\
\hline
\end{tabular}

${ }^{*} P<0.05,{ }^{* *} P<0.01$; Spearman's rho correlation

NGAL, neutrophil gelatinase-associated lipocalin ( $\mathrm{ng} / \mathrm{mL}$ ); cf-nDNA, cell-free nuclear DNA (GE/mL); GE/mL, genome equivalents $/ \mathrm{mL}$; urine $\mathrm{A} / \mathrm{C}$ ratio, urine albumin-creatinine ratio $(\mathrm{mg} / \mathrm{g})$; urine $\mathrm{P} / \mathrm{C}$ ratio, urine protein-creatinine ratio $(\mathrm{mg} / \mathrm{g})$ 
Table 6 Multivariate Predictors of urinary cf- nDNA

\begin{tabular}{|c|c|c|c|c|}
\hline \multirow[t]{2}{*}{ Predictors } & \multicolumn{2}{|c|}{ Unstandardized Coefficients } & \multirow{2}{*}{$\begin{array}{l}\text { Standardized Coefficients } \\
\text { Beta }\end{array}$} & \multirow[t]{2}{*}{$p$ value } \\
\hline & $B$ & Std. Error & & \\
\hline (Constant) & -14.839 & 24.831 & & 0.576 \\
\hline NGAL & -0.017 & 0.024 & -0.071 & 0.502 \\
\hline Urine protein & -0.144 & 0.150 & -0.463 & 0.380 \\
\hline Urine $\mathrm{A} / \mathrm{C}$ ratio & -0.074 & 0.019 & -2.214 & $0.013^{*}$ \\
\hline Urine $\mathrm{P} / \mathrm{C}$ ratio & 0.085 & 0.014 & 3.526 & $0.002^{* *}$ \\
\hline
\end{tabular}

$R^{2}=0.960 ; * P<0.05, * * P<0.01$

$\mathrm{NGAL}$, neutrophil gelatinase-associated lipocalin ( $\mathrm{ng} / \mathrm{mL}$ ); cf-nDNA, cell-free nuclear DNA (GE/mL); GE/mL, genome equivalents/mL; urine $\mathrm{A} / \mathrm{C}$ ratio, urine albumincreatinine ratio $(\mathrm{mg} / \mathrm{g})$; urine $\mathrm{P} / \mathrm{C}$ ratio, urine protein-creatinine ratio $(\mathrm{mg} / \mathrm{g})$

mitochondrial DNA. The DNA concentrations were expressed as genome equivalents $(\mathrm{GE}) / \mathrm{mL}$ of urine and plasma, where $1 \mathrm{GE}$ was equivalent to $6.6 \mathrm{ng}$ DNA [37]. Serially diluted human genomic DNA solution were used for preparing a six-point calibration curve [38].

\section{Plasma neutrophil gelatinase-associated lipocalin (NGAL)}

Plasma NGAL concentrations were measured using a commercially available assay kit (Immunology Consultants Laboratory, Inc., Oregon, USA).

\section{Statistical analysis}

Results are presented as the median (interquartile range) or number (proportion, \%). All data were analyzed by the ANOVA test, if $\mathrm{p}$ with significant will receive further post hoc test analysis. A multivariate linear regression model was used to evaluate independent associations between possible predictors and cf-mtDNA or cf-nDNA. Receiver operator characteristics (ROC) curve analysis was performed to assess different samples of cf-DNA and NGAL to predict renal disease related outcomes. Youden's index is the sum of sensitivity and specificity minus one, which is the most commonly used criterion for cut-off point selection in the context of ROC curve analysis. The maximum value of the index may be used as a criterion for selecting the optimum cut-off point. We used logistic regression to analyze the significant predictors of dissimilar renal outcome at 6 months. Statistical methods were employed to determine the appropriate number of patient and control samples required to ensure meaningful and statistically significant data (with a power of $80 \%$, a sample size of 38 was sufficient to detect an observed difference). All statistical analyses were performed using IBM SPSS 20 (SPSS, Inc., Chicago, IL, USA) and a qualified statistician was employed to determine which tests should be used and whether they performed the analysis. In all analyses, $P$ values of $<0.05$ were considered statistically significant.

\section{Results}

The demographic and clinical characteristics of the varying stages of chronic kidney diseases

Table 1 shows significant differences in age, renal functions, phosphate and low-density lipoprotein levels among varying stages of chronic kidney diseases and the further post hoc test analysis showed CKD stage related. High incidence, 37 to $59 \%$, of hypertension encounters in varying stage CKD patients. Concerning DM, the incidence is increasing comparable to CKD stage worsen, $12 \% \mathrm{DM}$ in early stage CKD and 54\% in stage 5 CKD.

The levels of cell-free mitochondrial (cf-mtDNA) and nuclear deoxyribonucleic acid (cf-nDNA), both urine and plasma, in varying stages of CKD patients

The plasma levels of neutrophil gelatinase-associated lipocalin (NGAL) significantly increase among the advanced stages of CKD (Table 2, Additional file 1: Fig. S1A). The plasma levels of cf-nDNA decrease as the renal function

Table 7 Multivariate Predictors of urinary cf- mtDNA

\begin{tabular}{|c|c|c|c|c|}
\hline \multirow[t]{2}{*}{ Predictors } & \multicolumn{2}{|c|}{ Unstandardized Coefficients } & \multirow{2}{*}{$\begin{array}{l}\text { Standardized Coefficients } \\
\text { Beta }\end{array}$} & \multirow[t]{2}{*}{$p$ value } \\
\hline & B & Std. Error & & \\
\hline (Constant) & -1.790 & 2.295 & & 0.471 \\
\hline NGAL & -0.001 & 0.002 & -0.049 & 0.597 \\
\hline Urine protein & -0.018 & 0.014 & -0.537 & 0.261 \\
\hline Urine $\mathrm{A} / \mathrm{C}$ ratio & -0.007 & 0.002 & -1.867 & $0.015^{*}$ \\
\hline Urine $\mathrm{P} / \mathrm{C}$ ratio & 0.008 & 0.001 & 3.277 & $0.002^{* *}$ \\
\hline
\end{tabular}

$R^{2}=0.969 ;{ }^{*} P<0.05$, * $P<0.01$

$\mathrm{NGAL}$, neutrophil gelatinase-associated lipocalin ( $\mathrm{ng} / \mathrm{mL}$ ); cf-mtDNA, cell-free mitochondrial DNA (GE/mL); GE/mL, genome equivalents/mL; urine $\mathrm{A} / \mathrm{C}$ ratio, urine albumin-creatinine ratio $(\mathrm{mg} / \mathrm{g})$; urine $\mathrm{P} / \mathrm{C}$ ratio, urine protein-creatinine ratio $(\mathrm{mg} / \mathrm{g})$ 


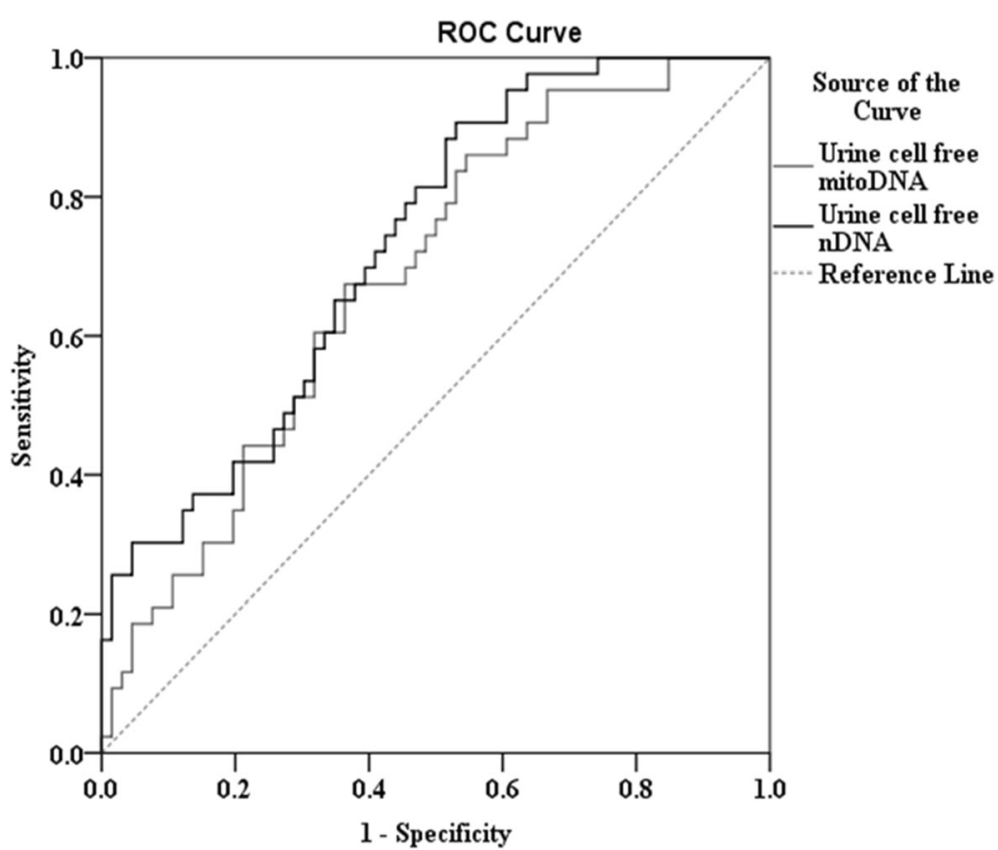

Fig. 1 Evaluation of urinary cf-nDNA and urine cf-mtDNA as predictors of CKD patient outcomes after 6 months. The areas under the curves (AUC) were as follows: urine cf-mtDNA: $0.685\left(0.586-0.784, P=0.001^{*}\right)$, and urine cf-nDNA: $0.730\left(0.637-0.823, P<0.001^{*}\right)$

Table 8 Logistic regression analysis of predictors of favorable renal outcome at 6 months

\begin{tabular}{lllllll}
\hline & B & S.E. & $P$ value & Odds ratio & $95 \%$ C.l. \\
\hline Module 1 & & & & & & \\
Baseline eGFR & .010 & .011 & .377 & 1.010 & .988 & 1.031 \\
Gender (male) & .044 & .494 & .929 & 1.045 & .396 & 2.753 \\
Age & .023 & .020 & .249 & 1.023 & 0.984 & 1.063 \\
NGAL & .001 & .001 & .152 & 1.001 & 1.000 & 1.003 \\
Urine cf-mtDNA & .596 & .266 & $.025^{*}$ & 1.815 & 1.076 & 3.059 \\
Constant & -2.543 & 1.632 & .119 & .079 & & \\
Module 2 & & & & & & \\
Baseline eGFR & .027 & .014 & .061 & 1.027 & .999 & 1.056 \\
Gender (male) & .278 & .587 & .636 & 1.320 & .417 & 4.175 \\
Age & .054 & .024 & $.027^{*}$ & 1.056 & 1.006 & 1.107 \\
NGAL & .002 & .001 & .110 & 1.002 & 1.000 & 1.004 \\
Urine cf-nDNA & .255 & .102 & $.012^{*}$ & 1.290 & 1.057 & 1.575 \\
Constant & -5.688 & 2.182 & .009 & .003 & & \\
\hline
\end{tabular}

${ }^{*} P<0.05$. Module 1: test urine cf-mtDNA as a covariate; Module 2: test urine cf-nDNA as a covariate

NGAL, neutrophil gelatinase-associated lipocalin ( $\mathrm{ng} / \mathrm{mL}) ; \mathrm{cf}-\mathrm{mtDNA}$, cell-free mitochondrial DNA (GE/mL); cf-nDNA, cell-free nuclear DNA (GE/mL); GE/mL, genome equivalents $/ \mathrm{mL}$ deterioration (Additional file 1: Figure S1B), in contrast to cfmtDNA and mitochondrial copy number (MCN), which is not significantly changed among varying stages of CKD patients. There was no significant changes in urinary cf-mtDNA and cf-nDNA levels for varying stages of CKD. Urinary 8-hydroxy- 2-deoxyguanosine (8-OHdG), a symbolic marker of oxidative stress, is also not significantly changed in our study. In post hoc analysis, the data reveals that base plasma cf-nDNA is significant higher in early CKD (stage 1 and 2) than other stages and base plasma NGAL level is higher in advanced CKD (stage 3b, 4 and 5) than early CKD.

\section{The difference of baseline parameters between different (favorable vs. unfavorable) renal outcome at 6 months (Table 3)}

There are significantly lesser levels of urinary cf-mtDNA, cf-nDNA and plasma NGAL in the favorable renal outcome group. The levels of urinary 8-hydroxy-2-deoxyguanosine (8-OHdG), plasma cf-mtDNA and plasma cfnDNA are not significantly different between favorable and unfavorable renal outcome groups.

\section{The correlation between urinary cf-nDNA, cf-mtDNA and variables}

As univariate analysis for the correlation between urinary cfnDNA, cf-mtDNA and variables (Tables 4 and 5, Additional file 2: Figure S2 and Additional file 3: Figure S3), the urinary cf-nDNA is significant correlation with urine PCR, urine ACR, urine protein, cf-mtDNA and plasma NGAL. 
Concurrently, the urinary cf-mtDNA is significant correlation with urine PCR, urine ACR, urine protein and cfmtDNA. In the multivariate analysis of predictors, we demonstrate that both urine $\mathrm{P} / \mathrm{C}$ ratio and $\mathrm{A} / \mathrm{C}$ ratio are the significant predictors for urinary cf-mtDNA and cfnDNA levels (Tables 6 and 7).

\section{Evaluation of urine cf-mtDNA, and urine cf-nDNA levels as predictors of CKD patient outcomes after 6 months}

Figure 1 shows the urinary cf-mtDNA and cf-nDNA levels as predictors of CKD patient outcomes after 6 months. The areas under the curves (AUC) were as follows: urine cf-mtDNA: $0.685\left(0.586-0.784, P=0.001^{*}\right)$, and urine cf-nDNA: $0.730\left(0.637-0.823, P<0.001^{*}\right)$. Both are better than plasma NGAL (data not shown). The optimal Youden's index-based cut-off point was estimated. Urine cf-mtDNA cut-off value was $0.893 \mathrm{GE} / \mathrm{mL}$, with sensitivity $0.860,1$ - specificity 0.545 , and Youden's index was 0.315 . Meanwhile, urinary cf-nDNA cut-off value was 3.116 $\mathrm{GE} / \mathrm{mL}$, with sensitivity 0.907 and $1-$ Specificity 0.530 , and Youden's index was 0.377 . Via logistic regression analysis, we confirmed that both urine cf-mtDNA and urine cfnDNA could be the significant predictors for dissimilar renal outcome (favorable vs. unfavorable) at 6 months (Table 8).

\section{Discussion}

To the best of our knowledge, this study is the first to show the clinical significant correlation between urine cf-mtDNA, urine cf-nDNA and divergent renal outcome at 6 months. We also propose that both urine PCR and ACR could significantly predict urinary cf-nDNA and cfmtDNA levels.

Our study showed greater amounts of cf-nDNA in earlier stage CKD, but no correlation between urinary nuclear and mitochondria cf-DNA and CKD staging. Otherwise, there were greater quantities of urinary cfnDNA and cf-mtDNA in the unfavorable renal outcome group. Our findings were consistent with the results from a diabetes population study that showed mtDNA was readily detectable in urinary supernatant and kidney tissue, and that its levels correlated with renal function and scarring in DN [39]. However, their study did not measure plasma cf-DNA levels or a correlation between urinary nuclear cf-DNA levels and DN prognosis.

The death of cells in the tissues is an active process that supports the homeostasis of tissues [40] and increase of cf-DNA in plasma might occur due to the enhancement of programmed cell death [41]. In AKI models, the activation of autophagy provided a significant contribution to the elimination of damaged cells from tissues [41]. Our CKD cohort findings of more plasma cf-DNA in earlier stage CKD suggested that low plasma cf-DNA in later stages, even stages $4-5$, indicated the deregulation or decompensation of programmed cell death by multifactorial mechanisms. As well-known, the process of autophagy is generally assumed to be a mechanism of survival or a cytoprotective mechanism that removes damaged organelles, proteins, and other macromolecules [42, 43]. An animal study showed that kidney epithelium and podocytes were sufficient to trigger a degenerative disease of the kidney with many of the manifestations of human focal segmental glomerulosclerosis, following the prevention of autophagic flux [11].

According to the results of a number of studies, cell death accompanied by the release of cf-DNA fragments into the blood and urine can occur through autophagy as well as mechanisms of apoptosis and necrosis [42, 43]. A variety of stress stimuli can induce autophagy process, such as infection, oxidative stress, starvation, hypoxia etc. The stimulation of autophagy by these stimuli produced cellular energy stress and activated 50-adenosine monophosphate activated protein kinase (AMPK) by sensing increases in AMP:ATP and ADP:ATP ratios [43, 44]. In a DN study, Dr. Wei found a statistically significant inverse correlation between urinary supernatant and intra-renal mtDNA levels [39]. These findings were inter-related to our results where high urinary cfDNA levels might be a marker to predict kidney tissue injury in CKD patients and a worse renal outcome. According multivariate analysis, we suggested that urine $\mathrm{P} / \mathrm{C}$ ratio and $\mathrm{A} / \mathrm{C}$ ratio are both the significant predictors for urinary cf-nDNA and cf-mtDNA levels. However, we did not find a statistically significant correlation between urinary cfDNA and CKD staging, possibly because of the relatively small population enrolled.

The detection of microalbuminuria is a standard method to diagnose the early stages of DKD; however, some patients with microalbuminuria have advanced renal disease [45]. Microalbuminuria is not as sensitive as invasive renal biopsy. There is an unmet need to identify non-invasive biomarkers of DKD in its early stages [45-49]. Our AUC analysis showed that urinary cf-nDNA and cf-mtDNA levels were reliable to predict renal function outcomes within 6 months.

Our findings were consistent with the positive correlation between NGAL levels and CKD staging. The NGAL gene product is a protein $(23-26 \mathrm{kDa})$ induced by triggers of acute kidney injury [50, 51]. NGAL is rapidly released from renal tubular cells in response to various insults to the kidney. In contrast, NGAL was recently shown to be useful in the quantitation and prediction of CKD [52, 53]. Bolignano et al. reported that NGAL closely reflected the entity of renal impairment and represented an independent risk marker for the progression of CKD [52]. Liu et al., however, demonstrated that urine NGAL levels did not predict progressive CKD [54]. NGAL is a member of the lipocalin family of proteins that has been extensively studied in acute kidney injury (AKI). NGAL is a robustly expressed protein in the kidney following ischemic or nephrotoxic injury in animals [55] and 
humans [56]. Via AUC analysis, we demonstrated that cfDNA might be more sensitive than well-known CKD biomarkers such as NGAL (data not shown).

There are several potential limitations to this study. First, a relatively low number of patients were investigated. Secondary, we conducted a cohort study for our clinical analysis of less than 12 months duration. Third, there was subject-to-selection bias and information on exposure was subject to observation bias from the statistic model. Only large-scale collaborative multicenter or international studies will identify important risk factors. Finally, other hard outcomes in more than 6 months, beside eGFR surrogate, could be conducted in future study.

\section{Conclusions}

In conclusion, both urinary cf-mtDNA and cf-nDNA should be novel biomarkers to predict the prognosis of chronic renal diseases. The levels of plasma cf-nDNA and NGAL were significantly correlated with the severity of CKD.

\section{Supplementary information}

The online version of this article (https://doi.org/10.1186/s12882-019-1549-x) contains supplementary material, which is available to authorized users.

Additional file 1. Figure S1. Box-whisker plots for plasma NGAL (Figure S1A) and plasma cf-nDNA (Figure S1B) levels in varying stages of CKD.

Additional file 2. Figure S2. Scatter-plots for correlation analysis between urinary cf-nDNA and different variables. Figure S2A Correlation between urine $\mathrm{Cf}-\mathrm{nDNA}$ and urine protein/creatinine ratio. Figure S2B Correlation between urine cf-nDNA and urine albumin/creatinine ratio. Figure S2C Correlation between urine cf-nDNA and urine protein ratio. Figure S2D Correlation between urine $\mathrm{cf}-\mathrm{nDNA}$ and plasma NGAL. Figure S2E Correlation between urine cf-nDNA and urine cf-mtDNA.

Additional file 3. Figure S3. Scatter-plots for correlation analysis between urinary cf-mtDNA and different variables. Figure S3A Correlation between urine cf-mtDNA and urine albumin/creatinine ratio. Figure S3B Correlation between urine cf-mtDNA and urine protein/creatinine ratio.

\section{Abbreviations}

8-OH dG: 8-hydroxy-2-deoxyguanosine; ACR: albumin-creatinine ratio; AKI: acute kidney injury; cf-DNA: cell-free DNA; cf-mtDNA: cell-free mitochondrial DNA; cf-nDNA: cell-free nuclear DNA; CKD: chronic kidney disease; DNA: deoxyribonucleic acid; eGFR: estimated glomerular filtration rate; eGFR $R_{C K D-F p \mid}$ : CKD- Epidemiology Collaboration equation; EMT: epithelialmesenchymal transition; ESRD: end stage renal disease; GE: genome equivalents; KDIGO: Kidney Disease Improving Global Outcomes; NGAL: neutrophil gelatinase-associated lipocalin; PCR: protein-creatinine ratio; ROC: Receiver operator characteristics

\section{Acknowledgements}

This project was supported by the Changhua Christian Hospital, Changhua, Taiwan. We thank Edanz Group (www.edanzediting.com/ac) for editing a draft of this manuscript.

\section{Authors' contributions}

C-HH, C-CC, and C-SL designed research; C-CC, C-LK, and C-SH conducted research; P-FC and C-LW analyzed data; C-HH, C-CC wrote the paper; C-HH, C$C C$, and C-SL had primary responsibility for final content. All authors read and approved the final manuscript.

\section{Funding}

This study was supported by 104-CCH-ICO-002 and 103-CCH-IRP-009 from Changhua Christian Hospital, Changhua, Taiwan. This funding body had no role in the design of this study and will not have any role during its collection, analyses, interpretation of the data, or decision to submit results.

\section{Availability of data and materials}

All data and materials are availability in the draft.

\section{Ethics approval and consent to participate}

All experimental protocols were approved by the Institutional Review Board of Changhua Christian Hospital (approval number 140306) and all the participants provided written informed consent to participate in the study.

\section{Consent for publication}

Not applicable.

\section{Competing interests}

The authors declare that they have no competing interests.

\section{Author details}

1Department of Internal Medicine, Kuang Tien General Hospital, Taichung, Taiwan. ${ }^{2}$ Department of Nutrition, Hungkuang University, Taichung, Taiwan. ${ }^{3}$ School of Medicine, Chung Shan Medical University, Taichung, Taiwan. ${ }^{4}$ Nephrology Division, Department of Internal Medicine, Changhua Christian Hospital, Changhua, Taiwan. ${ }^{5}$ Vascular \& Genomic Research Center, Changhua Christian Hospital, Changhua, Taiwan. ${ }^{6}$ Center of General Education Tunghai University, Taichung, Taiwan. ${ }^{7}$ Internal Medicine Research Center, Changhua Christian Hospital, Changhua, Taiwan. ${ }^{8}$ Department of Neurology, Changhua Christian Hospital, Changhua, Taiwan. ${ }^{9}$ Department of Cardiology, Changhua Christian Hospital, Changhua, Taiwan. ${ }^{10}$ Institute of Statistics and Information Science, National Changhua University of Education, Changhua, Taiwan. ${ }^{11}$ School of Medicine, College of Medicine, Kaohsiung Medical University, Kaohsiung, Taiwan. ${ }^{12}$ Department of Beauty Science and Graduate Institute of Beauty Science Technology, Chienkuo Technology University, Changhua, Taiwan.

Received: 25 February 2019 Accepted: 4 September 2019 Published online: 28 October 2019

\section{References}

1. Nallu A, Sharma S, Ramezani A, Muralidharan J, Raj D. Gut microbiome in chronic kidney disease: challenges and opportunities. Transl Res. 2017;179: 24-37. https://doi.org/10.1016/..trsl.2016.04.007.

2. Levey AS, Eckardt KU, Tsukamoto Y, Levin A, Coresh J, Rossert J, et al. Definition and classification of chronic kidney disease: a position statement from kidney disease: improving global outcomes (KDIGO). Kidney Int. 2005; 67:2089-100. https://doi.org/10.1111/j.1523-1755.2005.00365.x

3. Meguid El Nahas A, Bello AK. Chronic kidney disease: the global challenge. Lancet. 2005;365:331-40. https://doi.org/10.1016/S0140-6736(05)17789-7.

4. Bello AK, Nwankwo E, El Nahas AM. Prevention of chronic kidney disease: a global challenge. Kidney Int Suppl. 2005;98:S11-7. https:/doi..org/10.1111/1.1523-1755.2005.09802x

5. Gansevoort RT, Correa-Rotter R, Hemmelgarn BR, Jafar TH, Heerspink HJ, Mann JF, et al. Chronic kidney disease and cardiovascular risk: epidemiology, mechanisms, and prevention. Lancet. 2013;382:339-52. https://doi.org/10.1016/S0140-6736(13)60595-4.

6. Che R, Yuan Y, Huang S, Zhang A. Mitochondrial dysfunction in the pathophysiology of renal diseases. Am J Phys Renal Phys. 2013;306:F367-78. https://doi.org/10.1152/ajprenal.00571.2013.

7. Yuan Y, Chen Y, Zhang P, Huang S, Zhu C, Ding G, et al. Mitochondrial dysfunction accounts for aldosterone-induced epithelial-to-mesenchymal transition of renal proximal tubular epithelial cells. Free Radic Biol Med. 2012;53:30-43. https://doi.org/10.1016/j.freeradbiomed.2012.03.015.

8. Zhang A, Jia Z, Guo X, Yang T. Aldosterone induces epithelial mesenchymal transition via ROS of mitochondrial origin. Am J Physiol Ren Physiol. 2007; 293:F723-31. https://doi.org/10.1152/ajprenal.00480.2006.

9. Emma F, Montini G, Parikh SM, Salviati L. Mitochondrial dysfunction in inherited renal disease and acute kidney injury. Nat Rev Nephrol. 2016:12: 267-80. https://doi.org/10.1038/nrneph.2015.214.

10. Zhu C, Huang S, Yuan Y, Ding G, Chen R, Liu B, et al. Mitochondrial dysfunction mediates aldosterone-induced podocyte damage. A therapeutic 
target of PPAR gamma. Am J Pathol. 2011;178:2020-31. https://doi.org/10. 1016/j.ajpath.2011.01.029.

11. He L, Wei Q, Liu J, Yi M, Liu Y, Liu H, et al. AKI on CKD: heightened injury, suppressed repair, and the underlying mechanisms. Kidney Int. 2017;92: 1071-83. https://doi.org/10.1016/j.kint.2017.06.030.

12. Kawakami T, Gomez IG, Ren S, Hudkins K, Roach A, Alpers CE, et al. Deficient autophagy results in mitochondrial dysfunction and FSGS. J Am Soc Nephrol. 2015;26:1040-52. https://doi.org/10.1681/ASN.2013111202.

13. Gong W, Mao S, Yu J, Song J, Jia Z, Huang S, et al. NLRP3 deletion protects against renal fibrosis and attenuates mitochondrial abnormality in mouse with 5/6 nephrectomy. Am J Phys Renal Phys. 2016;310:F1081-8. https://doi. org/10.1152/ajprenal.00534.2015.

14. Hallan S, Sharma K. The role of mitochondria in diabetic kidney disease. Curr Diab Rep. 2016;16:61. https://doi.org/10.1007/s11892-016-0748-0.

15. Higgins $\mathrm{GC}$, Coughlan MT. Mitochondrial dysfunction and mitophagy: the beginning and end to diabetic nephropathy? Br J Pharmacol. 2014;171: 1917-42. https://doi.org/10.1111/bph.12503.

16. Mandel P, Metais P. Les acides du plasma sanguin chez l'homme. C R Acad Sci Paris. 1948;142:241-3 PMID:18875018.

17. Zhang $Q$, Raoof M, Chen Y, Sumi Y, Sursal T, Junger W, et al. Circulating mitochondrial DAMPs cause inflammatory responses to injury. Nature. 2010; 464:104-7. https://doi.org/10.1038/nature08780.

18. Oka T, Hikoso S, Yamaguchi O, Taneike M, Takeda T, Tamai T, et al. Mitochondrial DNA that escapes from autophagy causes inflammation and heart failure. Nature. 2012:485:251-U142. https://doi.org/10.1038/nature10992.

19. Nakahira K, Kyung SY, Rogers AJ, Gazourian L, Youn S, Massaro AF, et al. Circulating mitochondrial DNA in patients in the ICU as a marker of mortality: derivation and validation. PLoS Med. 2013;10:e1001577. https:// doi.org/10.1371/journal.pmed.1001577.

20. Tin A, Grams ME, Ashar FN, Lane JA, Rosenberg AZ, Grove ML, et al. Association between mitochondrial DNA copy number in peripheral blood and incident CKD in the atherosclerosis risk in communities study. J Am Soc Nephrol. 2016;27:2467-73. https://doi.org/10.1681/ASN.2015060661.

21. Cao H, Ye H, Sun Z, Shen X, Song Z, Wu X, et al. Circulatory mitochondrial DNA is a pro-inflammatory agent in maintenance hemodialysis patients. PLoS One. 2014:9:e113179. https://doi.org/10.1371/journal.pone.0113179.

22. Lo Y.M., Rainer T.H., Chan L.Y., Hjelm N.M., Cocks R.A.. (2000) Plasma DNA as a prognostic marker in trauma patients. Clin Chem 46, 319-323. PMID: 10702517.

23. Rainer TH, Lam NYL. Circulating nucleic acids and critical illness. Ann N Y Acad Sci. 2006;1075:271-7. https://doi.org/10.1196/annals.1368.035.

24. Antonatos D, Patsilinakos S, Spanodimos S, Korkonikitas P, Tsigas D. Cell-free DNA levels as a prognostic marker in acute myocardial infarction. Ann N Y Acad Sci. 2006;1075:278-81. https://doi.org/10.1196/annals.1368.037.

25. Rhodes A, Wort SJ, Thomas H, Collinson P, Bennett ED. Plasma DNA concentration as a predictor of mortality and sepsis in critically ill patients. Crit Care. 2006;10:R60. https://doi.org/10.1186/cc4894.

26. Saukkonen K, Lakkisto P, Varpula M, Varpula T, Voipio-Pulkki LM, Pettilä V, et al. Association of cell-free plasma DNA with hospital mortality and organ dysfunction in intensive care unit patients. Intensive Care Med. 2007;33: 1624-7. https://doi.org/10.1007/s00134-007-0686-z.

27. Hurtado-Roca Y, Ledesma M, Gonzalez-Lazaro M, Moreno-Loshuertos R, Fernandez-Silva P, Enriquez JA, et al. Adjusting MtDNA quantification in whole blood for peripheral blood platelet and leukocyte counts. PLoS One. 2016;11:e0163770. https://doi.org/10.1371/journal.pone.0163770.

28. Urata M, Koga-Wada Y, Kayamori Y, Kang D. Platelet contamination causes large variation as well as overestimation of mitochondrial DNA content of peripheral blood mononuclear cells. Ann Clin Biochem. 2008:45:513-4. https://doi.org/10.1258/acb.2008.008008.

29. Lee JE, Park H, Ju YS, Kwak M, Kim Jl, Oh HY, et al. Higher mitochondrial DNA copy number is associated with lower prevalence of microalbuminuria. Exp Mol Med. 2009;41:253-8. https://doi.org/10.3858/emm.2009.41.4.028.

30. Lu T, Li J. (2017) Clinical applications of urinary cell-free DNA in cancer: current insights and promising future. Am J Cancer Res 7, 2318-2332. PubMed PMID: 29218253; PubMed Central PMCID: PMC5714758.

31. Ho PWL, Pang WF, Luk CCW, Ng JKC, Chow KM, Kwan BCH, et al. Urinary mitochondrial DNA level as a biomarker of acute kidney injury. Kidney Dis. 2017;3:78-83. https://doi.org/10.1159/000475883.

32. Whitaker RM, Stallons LJ, Kneff JE, Alge JL, Harmon JL, Rahn JJ, et al. Urinary mitochondrial DNA is a biomarker of mitochondrial disruption and renal dysfunction in acute kidney injury. Kidney Int. 2015;88:1336-44. https://doi. org/10.1038/ki.2015.240.
33. Botezatu I, Serdyuk O, Potapova G, Shelepov V, Alechina R, Molyaka Y, et al. (2000) Genetic analysis of DNA excreted in urine: a new approach for detecting specific genomic DNA sequences from cells dying in an organism. Clin Chem 46, 1078-1084. PMID: 10926886.

34. Lichtenstein AV, Melkonyan HS, Tomei LD, Umansky SR. Circulating nucleic acids and apoptosis. Ann N Y Acad Sci. 2001;945:239-49. https://doi.org/10. 1111/j.1749-6632.2001.tb03892.x.

35. Levey, A.S., Coresh, J., Balk, E., Kausz, A.T., Levin, A., Steffes, M.W., et al. (2003) National Kidney Foundation practice guidelines for chronic kidney disease: evaluation, classification, and stratification. Ann Intern Med 139, 137-147. PMID: 12859163

36. Coresh J, Turin TC, Matsushita K, Sang Y, Ballew SH, Appel $\sqcup$, et al. Decline in estimated glomerular filtration rate and subsequent risk of end-stage renal disease and mortality. JAMA. 2014;311:2518-31. https://doi.org/10. 1001/jama.2014.6634.

37. Lo YM, Tein MS, Lau TK, Haines CJ, Leung TN, Poon PM, et al. (1998) Quantitative analysis of fetal DNA in maternal plasma and serum: implications for noninvasive prenatal diagnosis. Am J Hum Genet 62, 768-775. PubMed PMID: 9529358; PubMed Central PMCID: PMC1377040

38. García Moreira V, Prieto García B, de la Cera Martínez T, Alvarez Menéndez FV. Elevated transrenal DNA (cell-free urine DNA) in patients with urinary tract infection compared to healthy controls. Clin Biochem. 2009;42:729-31. https://doi.org/10.1016/j.clinbiochem.2008.12.021.

39. Wei PZ, Kwan BCH, Chow KM, Cheng PMS, Luk CCW, Li PKT, et al. Urinary mitochondrial DNA level is an indicator of intra-renal mitochondrial depletion and renal scarring in diabetic nephropathy. Nephrol Dial Transplant. 2018:33:784-8. https://doi.org/10.1093/ndt/gfx339.

40. Green DR, Llambi F. Cell death signaling. Cold Spring Harb Perspect Biol. 2015;7:a006080. https://doi.org/10.1101/cshperspect.a006080.

41. Tower J. Programmed cell death in aging. Ageing Res Rev. 2015;23:90-100. https://doi.org/10.1016/j.arr.2015.04.002.

42. Madeo F, Zimmermann A, Kroemer G, Kroemer G. Essential role for autophagy in life span extension. J Clin Invest. 2015;125:85-93. https://doi. org/10.1172/JCl73946.

43. Klionsky DJ, Abdelmohsen K, Abe A, Abedin MJ, Abeliovich H, Acevedo Arozena A, et al. Guidelines for the use and interpretation of assays for monitoring autophagy (3rd edition). Autophagy. 2016;12:1-222. https://doi. org/10.1080/15548627.2015.1100356.

44. Kroemer $\mathrm{G}$, Marino $\mathrm{G}$, Levine B. Autophagy and the integrated stress response. Mol Cell. 2010;40:280-93. https://doi.org/10.1016/j.molcel.2010.09.023.

45. Jin J, Ku YH, Kim Y, Kim Y, Kim K, Lee JY, et al. Differential proteome profiling using ITRAQ in microalbuminuric and normoalbuminuric type 2 diabetic patients. Exp Diabetes Res. 2012;2012:168602. https://doi.org/ 10.1155/2012/168602.

46. Varghese SA, Powell TB, Budisavljevic MN, Oates JC, Raymond JR, Almeida JS, et al. Urine biomarkers predict the cause of glomerular disease. J Am Soc Nephrol. 2007;18:913-22. https://doi.org/10.1681/ASN.2006070767.

47. Guo Z, Liu X, Li M, Shao C, Tao J, Sun W, et al. Differential urinary glycoproteome analysis of type 2 diabetic nephropathy using 2D-LC-MS/MS and iTRAQ quantification. J Transl Med. 2015;13:371. https://doi.org/10.1186/ s12967-015-0712-9.

48. Chien HY, Chen CY, Chiu YH, Lin YC, Li WC. Differential microRNA profiles predict diabetic nephropathy progression in Taiwan. Int J Med Sci. 2016;13: 457-65. https://doi.org/10.7150/ijms.15548.

49. Harder JL, Hodgin JB, Kretzler M. Integrative biology of diabetic kidney disease. Kidney Dis (Basel). 2015;1:194-203. https://doi.org/10.1159/ 000439196.

50. Nickolas TL, O'Rourke MJ, Yang J, Sise ME, Canetta PA, Barasch N, et al. Sensitivity and specificity of a single emergency department measurement of urinary neutrophil gelatinase-associated lipocalin for diagnosing acute kidney injury. Ann Intern Med. 2008;148:810-9. 18519927.

51. Paragas N, Qiu A, Zhang Q, Samstein B, Deng SX, Schmidt-Ott KM, et al. The Ngal reporter mouse detects the response of the kidney to injury in real time. Nat Med. 2011;17:216-22. https://doi.org/10.1038/nm.2290.

52. Bolignano D, Lacquaniti A, Coppolino G, Donato V, Campo S, Fazio MR, et al. Neutrophil gelatinase-associated lipocalin (NGAL) and progression of chronic kidney disease. Clin J Am Soc Nephrol. 2009:4:337-44. https://doi. org/10.2215/CJN.03530708

53. Malyszko J, Malyszko JS, Bachorzewska-Gajewska H, Poniatowski B, Dobrzycki S, Mysliwiec M. Neutrophil gelatinase associated lipocalin is a new and 
sensitive marker of kidney function in chronic kidney disease patients and renal allograft recipients. Transplant Proc. 2009;41:158-61. https://doi.org/10. 1016/j.transproceed.2008.10.088.

54. Liu KD, Yang W, Anderson AH, Feldman HI, Demirjian S, Hamano T, et al. Chronic renal insufficiency cohort (CRIC) study investigators: urine neutrophil gelatinase-associated lipocalin levels do not improve risk prediction of progressive chronic kidney disease. Kidney Int. 2013;83:909-14. https://doi.org/10.1038/ki.2012.458.

55. Mishra, J., Qing, M., Prada, A., Zahedi, K., Yang, Y., Barasch, J., et al. (2003) Identification of NGAL as a novel early urinary marker for ischemic renal injury. J Am Soc Nephrol 14, 2534-2543. PMID: 14514731.

56. Mori K, Lee HT, Rapoport D, Drexler I, Foster K, Yang J, et al. Endocytic delivery of lipocalin-siderophore-iron complex rescues the kidney from ischemia-reperfusion injury. J Clin Invest. 2005;115:610-21. https://doi.org/10.1172/JC123056.

\section{Publisher's Note}

Springer Nature remains neutral with regard to jurisdictional claims in published maps and institutional affiliations.

Ready to submit your research? Choose BMC and benefit from:

- fast, convenient online submission

- thorough peer review by experienced researchers in your field

- rapid publication on acceptance

- support for research data, including large and complex data types

- gold Open Access which fosters wider collaboration and increased citations

- maximum visibility for your research: over $100 \mathrm{M}$ website views per year

At $\mathrm{BMC}$, research is always in progress.

Learn more biomedcentral.com/submissions 